\title{
Los archivos de inteligencia en Argentina
}

\author{
Intelligence archives in Argentina
}

\author{
Mariana Nazar \\ mariananazar@gmail.com \\ Dirección de Gestión del Conocimiento, \\ Investigaciones y Publicaciones del Instituto Nacional \\ de la Administración Pública (INAP), Escuela de \\ Política y Gobierno, Universidad Nacional de San \\ Martín (EpyG-UNSAM) / Asociación de Archivistas \\ en la Función Pública Argentina (AFPA), Argentina
}

\section{Cecilia Garcia Novarini}

cgnovarini@gmail.com

Archivo Nacional de la Memoria (ANM), Escuela de

Política y Gobierno, Universidad Nacional de San

Martín (EpyG-UNSAM) / Asociación de Archivistas en la Función Pública Argentina (AFPA), Argentina

Recepción: 16 Abril 2021

Aprobación: 15 Mayo 2021

Publicación: 01 Junio 2021

Cita sugerida: Nazar, M. y Garcia Novarini, C. (2021). Los archivos de inteligencia en Argentina . Aletheia, 11(22), e084. https://doi.org/10.24215/18533701e084
Resumen: Este artículo propone abordar los archivos de inteligencia desde una perspectiva archivística incorporándola a modo de sistema de interpretación a partir de utilizar sus principios y algunos de los conceptos y procedimientos que la integran. Para ello, presenta brevemente el lugar que han ocupado las demandas por memoria, verdad y justicia en la identificación y puesta a la consulta de documentación de inteligencia en la Argentina; desarrolla la especificidad del marco conceptual archivístico para pensar la producción, gestión e investigación de este tipo de documentos; realiza un recorrido por los diferentes casos de archivos de inteligencia de los que se tiene conocimiento; analiza las consecuencias que las formas de conceptualizar el Archivo han tenido sobre las tareas de gestión e investigación; y problematiza las posibilidades de indagación sobre los mismos. De esa manera, se busca destacar la importancia de valorar los conceptos referidos a la principal y primera tarea de tratamiento archivístico: la identificación; a los fines de focalizar la mirada en cuestiones vinculadas a las posibilidades de recuperar el contexto de producción de los documentos y, de esa manera, habilitar la lectura de la información literal que portan los registros en diálogo con sus contextos. Entendiendo que es a partir de ello que se abre la posibilidad de que los documentos puedan servir tanto como fuente para la historia, como para la memoria institucional y/o para la garantía en el ejercicio de derechos de todas y todos.

Palabras clave: Archivos, Inteligencia, Archivística, Investigación, Represión.

Abstract: This article proposes to approach intelligence archives from an archival perspective, incorporating it as a system of interpretation by using its principles and some of its concepts and procedures. To this end, it briefly presents the place occupied by the demands for memory, truth and justice in the identification and consultation of intelligence documentation in Argentina; develops the specificity of the archival conceptual framework for thinking about the production, management and research of this type of documents; reviews the different cases of intelligence archives that are known; analyzes the consequences that the ways of conceptualizing the archive have had on the tasks of management and research; and problematizes the possibilities of research on them. In this way, it seeks to highlight the importance of valuing the concepts related to the main and first task of archival treatment: identification, in order to focus on issues related to the possibilities of recovering the context of production of the documents and, in this way, to 
enable the reading of the literal information contained in the records in dialogue with their contexts. It is understood that this opens up the possibility that the documents can serve as a source for history, as well as for institutional memory and/or for guaranteeing the exercise of the rights of all men and women.

Keywords: Archives, Intelligence, Archival science, Research, State violence.

\section{INTRODUCCIÓN}

Este artículo busca presentar una serie de conceptos fundamentales propios de la disciplina archivística que pueden ser útiles a la hora de analizar archivos generados por áreas de inteligencia, así como llamar la atención sobre ciertos recaudos a considerar en caso de gestionarlos.

Teniendo en cuenta que los archivos de inteligencia que se encuentran disponibles en nuestro país lo han sido, en su mayoría, como producto de secuestros u órdenes judiciales, resultado más de movilizaciones y decisiones políticas que de transferencias ordenadas; una característica común en términos de tratamiento documental es que suelen encontrarse en forma dispersa, fragmentada o sin registro respecto a sus contextos de producción. En algunos casos, esta situación ha llevado a orientar las tareas para facilitar el acceso centrándose sobre los documentos en forma individual. Asimismo, el secreto, la opacidad y la utilización de codificaciones, tanto en sus escritos como respecto de los procedimientos administrativos han llevado muchas veces a intuir que no hay una lógica de producción, sino que son producto de recogidas de información random.

En este texto convocamos a pensar los archivos desde una perspectiva archivística. Esto no significa que se requiera conocer cabalmente o estudiar la disciplina, sino incorporarla a modo de sistema de interpretación, utilizando sus principios y algunos de los conceptos y procedimientos que la integran. Entendemos que abordar los archivos de inteligencia desde esta perspectiva implica incorporar la funcionalidad de los mismos a la investigación y esto amplía las fronteras de los usos que pueden ofrecer. Eso lleva, por ejemplo, a reflexionar críticamente respecto a conceptos tales como archivos de la represión o del terror, así como a analizarlos sin acotarlos a determinados periodos de gobierno, lo que permite amplificar los aportes que estos archivos pueden dar a múltiples temas de investigación. ${ }^{1}$

Para ello, vamos a presentar los principios básicos de la disciplina, la definición que utiliza de archivo e introducir una serie de conceptos referidos a la principal y primera tarea de tratamiento archivístico: la identificación; a los fines de suscitar la reflexión sobre cuestiones vinculadas a las posibilidades de recuperar el contexto de producción de los documentos y, de esa manera, habilitar la lectura de la información literal que portan los registros en diálogo con sus contextos.

Para realizar este ejercicio, abordaremos el lugar que han ocupado las demandas por memoria, verdad y justicia en la identificación y puesta al acceso de documentación de inteligencia, exponiendo los casos conocidos hasta el momento; luego realizaremos una presentación general de la especificidad del marco conceptual archivístico para pensar la producción, gestión e investigación de este tipo de documentos y desarrollar dos casos -en los que ambas autoras fuimos parte activa de sus procesos- el de la Comisión Provincial por la Memoria y el del Archivo Nacional de la Memoria, que permitirán repensar las consecuencias que las formas de conceptualizar la tarea de gestión e investigación tienen sobre las posibilidades de indagación que nos brindan estos archivos. 


\section{La demanda social de Memoria, Verdad Y Justicia $Y$ Los hallazgos de DOCUMENTACIÓN DE INTELIGENCIA}

Desde antes de finalizada la última dictadura cívico militar que se vivió en Argentina, familiares, sobrevivientes, organizaciones y personas comprometidas con la militancia política o la defensa de los derechos humanos reclaman el acceso a la documentación generada durante la misma que dé cuenta del accionar del Estado y del destino de los y las desaparecidas.

Mientras las Fuerzas Armadas y de Seguridad han afirmado históricamente que se eliminó toda la documentación de la época referida al accionar represivo, señalando la normativa sancionada en los últimos días de la Dictadura, algunos hallazgos esporádicos evidenciaron que era necesario continuar las búsquedas.

Así es como una de las demandas más fuertes que la sociedad viene realizando en relación con las exigencias de Memoria, Verdad y Justicia ha sido la de que se abran los archivos, y fue gracias a esa movilización de tantos años que se han identificado y puesto al acceso algunos de los archivos de servicios de inteligencia. Sin embargo, los documentos que se reclaman, aquellos que den cuenta del destino de los desaparecidos/ as y de los hijos/as apropiados/as, como los expedientes y fichas generados en la ESMA mencionados por testimoniantes en el Juicio a las Juntas, ${ }^{2}$ aún no han sido hallados.

Las respuestas desde el Estado a este reclamo no han sido lineales y atravesaron avances y retrocesos en los diferentes gobiernos. En ese sentido, es de destacar el lugar otorgado a los documentos de archivo en las políticas de memoria implementadas durante los tres gobiernos kirchneristas. Como ya ha sido señalado en trabajos anteriores (Nazar, 2006, 2008, 2010, 2018, 2021) estas políticas de memoria, justicia y reparación no vinieron acompañadas de políticas públicas archivísticas sostenidas en el tiempo que lograran un acceso igualitario a los Archivos.

Un ejemplo de ello puede ser el hecho de que los archivos de inteligencia de las Fuerzas Armadas sigan sin ser accesibles, a pesar tanto de las políticas implementadas desde el Ministerio de Defensa para poner a la consulta pública los acervos de las Fuerzas Armadas ${ }^{3}$ como de la sanción y reglamentación de la Ley de Acceso a la Información (Ley No 27.275). En el caso de los archivos de las Fuerzas Federales de Seguridad, recién se está iniciando un proyecto para identificar y dar a conocer a toda la ciudadanía los documentos que preservan las mismas. ${ }^{4}$

A continuación, presentaremos los archivos de organismos de inteligencia o de informaciones que se encuentran disponibles para su consulta y/o que han sido identificados y fueron usados como prueba en juicios por delitos de lesa humanidad.

El primero fue el fondo documental de la Dirección General de Informaciones (DGI) ${ }^{5}$ de la Provincia de Santa Fe. A pesar del gran despliegue mediático realizado en función de su supuesto descubrimiento en el año 2009 (Galiano, 2009), ya en 1987 el Archivo Intermedio de la Provincia -en el marco de un trabajo de identificación y evaluación de series documentales- habría relevado las que se conservaban de la Dirección General de Informaciones, estableciendo su guarda permanente por Decreto Provincial $N^{\circ} 2816 / 89$, sin determinar grados de acceso. En 1993, el mismo decreto que derogaba la creación de la Central de Inteligencia de la Provincia (CIP) mencionaba en sus considerandos que en el sinergiagrama de la misma figuraban organismos desaparecidos al presente, como la DGI. Según señala Gabriela Aguila "la DGI no tuvo fecha de defunción ni fue disuelta, más bien se desintegró lentamente por la pérdida de funciones específicas y de personal (...) desapareció tan silenciosamente como había surgido y existido" (Aguila, 2013, p. 22). Luego, siguiendo el procedimiento reglado por la normativa archivística provincial, la documentación pasó a depender del Archivo General de la Provincia y fue transferida al Archivo Intermedio en el año 1995. En 1999 se abrió a la consulta para afectados/as directos/as y familiares (por derecho de hábeas data) e investigadores/ as acreditados/as y se autorizó el retiro de fichas originales de antecedentes estableciéndose un libro de registro para ello, ${ }^{6}$ luego de haberse dedicado las Jornadas de Archiveros de Santa Fe a debatir la cuestión de los 
archivos y los datos sensibles. Con la creación del Archivo Provincial de la Memoria (APM) dependiente de la Secretaría de Derechos Humanos, por Decreto provincial No2775/06, se comenzó a transferir el fondo a esta institución. En el año 2007 fue reconocido, por una presentación conjunta del Archivo Nacional de la Memoria, en el Programa Memoria del Mundo de UNESCO. En 2009 se completó el traslado hacia la sede del $\mathrm{APM},{ }^{7}$ y se dispuso para su consulta en el año 2012.

El fondo documental se compone de los documentos producidos por la DGI en el desarrollo de sus funciones durante su existencia, constituyendo un total de 16 metros lineales. Se encuentran documentos que dan cuenta del intercambio con dependencias gubernamentales, policiales y militares a las que se solicitaba y/o enviaba información referida a personas, hechos o entidades. La información recolectada en general se sistematizaba en fichas, informes o partes producidos por el organismo; también contiene documentación recolectada para la realización de informes.

El siguiente archivo identificado fue el de la Dirección de Inteligencia de la Policía de la Provincia de Buenos Aires (DIPPBA), el caso más conocido de la Argentina. ${ }^{8}$ DIPPBA es el último nombre de una larga serie de denominaciones de este organismo de inteligencia, nacido en 1956 y disuelto en 1998, que tiene antecedentes que se remontan a los inicios del siglo XX. Sobre el mismo, desarrollaremos más adelante.

Difundida su existencia en 1998, cuando fue identificado por funcionarios del ex Ministro de Justicia y Seguridad León Arslanian al disolver el área, los documentos quedaron a cargo de la Cámara Federal de La Plata que dictó una medida de no innovar, en el marco de los Juicios por la Verdad que investigaba el destino de más de 2000 desaparecidas/os. Integrantes del Equipo de Antropología Forense fueron nombrados peritos para abordar el fondo documental, de manera de aportar información a la Cámara. En el año 1999, a instancias de un proyecto presentado por la periodista y hoy diputada Gabriela Cerruti y el entonces presidente de la Cámara de Diputados de la provincia Alejandro Mosquera, se creaba como Comisión parlamentaria la que luego sería institucionalizada como Comisión Provincial por la Memoria. En agosto de 2000 fue creada por ley como organismo extrapoderes, autónomo y autárquico del gobierno provincial y meses más tarde, por otra ley, se le asignaba la función de preservar y poner a disposición del público el archivo de la DIPPBA. Abierto a la consulta pública desde 2003, ha aportado documentos para la reparación de víctimas y el desarrollo de las causas judiciales en relación con la última dictadura militar y otros procesos represivos; así como ha permitido el desarrollo de una multiplicidad de investigaciones históricas, sociales, culturales realizadas tanto por investigadores/as acreditados/as como por personas interesadas en la temática. El caso de la DIPBBA, y su puesta al acceso desde la CPM, tuvo una gran incidencia política. Fue, de alguna manera, la apertura de una línea específica de búsqueda de documentación.

Este caso impulsó un mayor esfuerzo en el hallazgo de documentación generada por las áreas policiales dedicadas a tareas de recopilación y procesamiento de información, es decir a la inteligencia. Dentro de las policías provinciales, se concentró en los Departamentos de Informaciones Policiales, identificados al interior de la estructura orgánica con el código D2. Los fondos documentales de estos organismos conocidos públicamente hasta el momento son los correspondientes a las Policías de las provincias de Santiago del Estero, Mendoza y San Juan.

En el caso del Departamento de Informaciones (D-2) de la Policía de la Provincia de Mendoza, ${ }^{9}$ la documentación se encontró en sus instalaciones en 1998, donde también funcionó el Centro Clandestino de Detención (CCD) más importante de dicha provincia. Los documentos permanecieron en el Ministerio de Gobierno, quien comunicó a través de la prensa que quienes desearan "recuperar su legajo", esto es retirar el legajo que contenía información sobre ellas/os, tenían un tiempo determinado para buscarlos. Pasado ese lapso, informaron que aquellos no retirados serían incinerados. El 12 de septiembre de 2002 abogados pertenecientes al CELS propusieron que los mismos permanezcan en una universidad y ofrecieron su colaboración para preservarlos. A partir de ese momento, organismos y activistas de derechos humanos de la provincia se propusieron realizar la misma tarea que se llevó adelante en La Plata con la documentación de la DIPPBA y se recibió su visita y asesoramiento. El 23 de diciembre de 2002 se presentó la ley de creación de 
una Comisión Provincial por la Memoria y recién en julio del 2004 fue aprobada en el recinto de diputados, pasando a senadores (sin presupuesto, ni inmueble asignados).

El 4 de abril de 2003 se firmó un convenio entre el Rectorado de la Universidad Nacional de Cuyo y el Ministerio de Gobierno de la provincia, mediante el cual la universidad se constituía en depositaria provisoria del archivo hasta tanto fuera sancionada la ley. El 19 de febrero de 2004 en una audiencia en el Rectorado se ofreció el asesoramiento de técnicos de la Universidad Nacional de Cuyo, el equipamiento para ordenar los legajos y carpetas y se oficializó el nombramiento de la persona responsable del archivo. La organización no gubernamental Casa por la Memoria y la Cultura Popular participó activamente del ordenamiento y primeras investigaciones de la documentación del fondo y elaboró los primeros instrumentos de descripción. Más tarde, la universidad llevó adelante la digitalización de los legajos. El archivo del D-2 ha sufrido varios traslados por lo que está deteriorado, recién en el año 2015 el Ministerio de la Gobernación de la provincia terminó de transferir toda la documentación a la Comisión Provincial por la Memoria que fue creada en 2009.

El fondo consiste en 2.354 legajos, 168 biblioratos denominados “casos" y 24 cajas de fichas. Del período 1972-1989, contiene libros de detenidos, sobres con negativos de fotos de detenidos y hechos, fichas necrodactilares, pericias, libros de criminalística, libros de rastros, libros de novedades del gabinete fotográfico y libros de novedades de infantería. Aún no se ha disponibilizado su consulta pública.

En el caso de Santiago del Estero, ${ }^{10}$ los documentos fueron encontrados en 2004, cuando el juez Ángel Jesús Toledo allanó el lugar donde funcionaba la D2 y secuestró el acervo. La documentación fue puesta bajo custodia de la Gendarmería Nacional que la depositó en una habitación del Puesto Móvil N5, expuesta a la humedad y a la caída de mampostería.

En 2014 se promovió un Convenio de Cooperación, Transferencia y Asistencia Científica Tecnológica entre la Procuración General de la Nación y la Universidad Nacional de Santiago del Estero. Desde ese entonces, el Grupo de Investigación en Derechos Humanos del Instituto de Estudios para el Desarrollo Social de la Facultad de Humanidades, Ciencias Sociales y de la Salud (FHCSyS) de la Universidad Nacional de Santiago del Estero y la Fiscalía están trabajando con el fondo.

Hasta julio de 2015, los únicos que tuvieron acceso directo al archivo fueron los funcionarios del Juzgado, la Gendarmería -quien por orden del juez elaboró un inventario- y, a partir de la firma del convenio mencionado, el equipo interinstitucional. Los documentos estuvieron prácticamente abandonados en el depósito de la Gendarmería Nacional hasta 2016 que fueron trasladados a la Subsecretaría de Justicia del gobierno provincial, edificio que antes era la antigua sede de la D2. ${ }^{11}$

Por el momento, se conoce que el fondo se compone de 17 ficheros metálicos que contienen 40 mil legajos de personas con sus antecedentes y no se ha dispuesto aún su consulta pública.

En la Provincia de San Juan, el fondo fue entregado por la propia policía al Tribunal Oral Federal de San Juan ${ }^{12}$ en el marco del primer megajuicio por delitos de lesa humanidad de la provincia, en el cual se juzgaban los casos de desaparición, tormentos y torturas de Marie Anne Erize, Hugo Ricardo Bustos, Alberto Carvajal y Margarita Camus (Causa $N^{\circ} 1077$ y acumuladas), cuya sentencia se produjo en septiembre del 2013. Posteriormente al juicio, 78 cajas de documentación fueron enviadas al Archivo Nacional de la Memoria (ANM) el 23 de diciembre del 2014. El fondo estuvo bajo custodia del ANM entre fines de 2014 y mediados de 2019, momento en el que fue remitido a la Subsecretaría de Derechos Humanos de la Provincia de San Juan. La Subsecretaría se encuentra desde mayo del 2020 recibiendo el asesoramiento de la Comisión Provincial por la Memoria de la Provincia de Buenos Aires y el Archivo Nacional de la Memoria para lograr una correcta identificación, clasificación, descripción y puesta a la consulta pública del acervo. Este trabajo en conjunto se está desarrollando para intentar recuperar el contexto de producción y el orden original del fondo desde el momento de su creación, ya que una vez transferido por la Policía Provincial, fue intervenido por el Tribunal Oral de San Juan, el ANM y la Subsecretaría de Derechos Humanos de dicha Provincia. 
La documentación del D2 se compone de los documentos que produjo el Departamento entre 1956 y 2003 (principalmente 1965-1987), en el cumplimiento de sus funciones. Como se encuentra en proceso de identificación, por el momento se puede constatar solamente la existencia de fichas e informes de antecedentes y recortes periodísticos vinculados al seguimiento de personas y actividades de universidades, partidos políticos, gremios, sindicatos, entidades religiosas, entre otros.

En la Provincia de Chubut, durante los trabajos de refacción de la Casa de Gobierno de la provincia realizados en el verano entre 1998 y 1999, una empleada estatal encontró y rescató los documentos del Servicio de Informaciones de Chubut. La documentación fue encontrada de forma desordenada, en condiciones de abandono. No fue hasta el 24 de marzo de 2004 cuando este acervo tomó estado público, a partir del anuncio realizado por el entonces gobernador Mario Das Neves. A partir de ese momento, los documentos fueron digitalizados y preservados en la bóveda del Banco del Chubut y se impulsó la creación del Archivo Provincial de la Memoria, formalizado mediante el Decreto Provincial No 1661 de septiembre de ese año. ${ }^{13}$

El acervo está compuesto por documentación de índole organizativa respecto a las formas de recopilar, gestionar y circular la información; minutas de simposios y recomendaciones sobre cuestiones de seguridad. Asimismo, se encuentran síntesis de antecedentes de personas, informes de actividades políticas, sociales y culturales. Permanece a cargo del APM Chubut. Está disponible para su consulta, a excepción de los datos personales que son disociados, accediéndose a partir de la presentación de una nota en la que se explicitan los motivos.

En relación con los archivos vinculados a las áreas de Inteligencia de las Fuerzas de Seguridad Federales y Fuerzas Armadas, como fue mencionado anteriormente, se tiene conocimiento que los archivos de las Jefaturas II de Inteligencia de cada Fuerza no entraron dentro del trabajo de relevamiento y apertura impulsado por el Ministerio de Defensa, invocando razones vinculadas a la clasificación de seguridad de dicha documentación en virtud de la Ley Nacional de Inteligencia. Solamente se obtuvo acceso al listado y legajos de algunos agentes del régimen de Personal Civil de Inteligencia del Estado, y de militares de esa especialidad, pero los documentos producidos en el cumplimiento de las funciones y misiones de cada órgano de inteligencia aún no han sido siquiera relevados.

La Ley de Acceso a la Información Pública habilita su apertura al establecer su capítulo de excepciones. ${ }^{14}$ $\mathrm{Su}$ decreto reglamentario, No206/2017, establece que en caso de no existir previsión en contrario, la información clasificada como reservada, confidencial o secreta mantendrá ese estado durante diez años desde su producción, transcurridos los cuales, el sujeto obligado deberá formular un nuevo análisis respecto de la viabilidad de desclasificar la información a fin de que alcance estado público. Sin embargo, dicha documentación permanece inaccesible.

De la documentación de inteligencia de las fuerzas de seguridad nacionales, únicamente se encuentra disponible para su consulta el fondo documental de la Sección Informaciones del Servicio de Inteligencia de Prefectura Zona Mar Argentino Norte, en la Comisión Provincial por la Memoria de la Provincia de Buenos Aires.

La misma fue identificada en octubre de 2005, cuando la Fiscalía General de Bahía Blanca a cargo del Dr. Hugo Omar Cañón se constituyó en dependencias de la Prefectura Naval Argentina Bahía Blanca con el fin de recabar información sobre las actividades desplegadas por las fuerzas de seguridad durante el período de la última dictadura militar. Al localizar papeles incinerados, el Ministerio Público Fiscal decidió trasladar parte de la documentación a la CPM con la finalidad de preservar el acervo. ${ }^{15}$ En noviembre de 2005 , el Archivo Nacional de la Memoria solicitó que se le entregue lo hallado en el cuarto denominado "pañol y archivo general Prefectura Zona Mar Argentino Norte". Tres cajas con documentación fueron trasladadas al ANM, dejándose constancia del hecho a través de un Acta. El resto de los documentos hallados fueron transferidos de la Fiscalía a la Comisión Provincial por la Memoria, con el objeto de digitalizarla y resguardarla. En 2009 
la Fiscalía General determinó que el fondo en su totalidad debía quedar bajo resguardo de la CPM, por lo que en septiembre de dicho año el ANM le transfirió la documentación que tenía bajo su guarda.

Los documentos que se preservan corresponden al archivo de la Sección Informaciones del Servicio de Inteligencia de Prefectura Zona Mar Argentino Norte, del período 1951 a 1998. Consta de un total de 87 cajas y más de 75000 fojas. Se encuentran las comunicaciones establecidas entre esta sección (o de las distintas dependencias de la Prefectura Naval Argentina), con la comunidad informativa o con otras instituciones, incluso de la esfera privada. Las temáticas que se encuentran en la documentación son variadas; figuran antecedentes de personas, pero es mayor el volumen de memos e informes sobre actividad portuaria y de gestión administrativa, predomina la documentación referida a las localidades de Bahía Blanca y Mar del Plata, pero por las características del fondo surge información de toda la provincia de Buenos Aires y hay referencias de Capital Federal.

Un caso excepcional es el del archivo de la oficina de inteligencia de la Base Aeronaval Almirante Zar, ${ }^{16}$ ya que se trata del único archivo de inteligencia militar que, aún hoy, se encuentra en poder de la justicia. El archivo fue secuestrado durante el allanamiento en el marco de la causa CELS s/denuncia, en marzo de 2006, cuando un suboficial denunció que allí se realizaban tareas de inteligencia que no se condecían con lo establecido en la legislación vigente sobre Defensa Nacional, Seguridad Interior e Inteligencia Nacional (leyes que restringen el accionar de las fuerzas armadas en los asuntos de política interna). El allanamiento puso en poder de la justicia un archivo que no ha tenido tratamiento archivístico y que tampoco se encuentra accesible a la consulta pública ya que permanece bajo custodia judicial.

Las fechas extremas son 1985-2006 (principalmente 1999-2006) y se trata de un conjunto de documentos que se encontraban en dos muebles archivadores, una caja fuerte y diversos biblioratos, así como documentación contenida en computadoras, y que incluye recortes periodísticos agrupados en carpetas, e informes dirigidos a la jerarquía naval de inteligencia organizados bajo factores o ámbitos: social, económico, político, minorías, entre otros. Se destaca asimismo la producción de material de seguimiento sobre las actividades conmemorativas de los familiares de los muertos en la masacre de Trelew (1972). ${ }^{17}$

Por último, respecto a documentos de inteligencia en Córdoba no se encuentra información de su existencia en el sitio web del Archivo Provincial de la Memoria de Córdoba, ni otras referencias en relación con sus condiciones de acceso. Sin embargo, pueden encontrarse artículos publicados por investigadoras que dan cuenta de haber accedido a los mismos en dicho APM (Tello 2019, Ortiz 2020).

Estos son los archivos producidos por organismos de informaciones o inteligencia sobre los cuales, hasta ahora, tenemos conocimiento público en la Argentina. Sin embargo, como puede verse en el artículo de Fernández Marrón y Berardi en este mismo dossier, en otros fondos -como el del Ministerio del Interior, Secretos, Confidenciales y Reservados; o Subsecretaría del Interior del Ministerio del Interior, que se presentará más adelante- o series documentales -como los prontuarios policiales- pueden hallarse huellas o indicios de su accionar.

\section{DESDE LA PERSPECTIVA ARCHIVÍSTICA: INFORMACIÓN LITERAL E INFORMACIÓN CONTEXTUAL}

Como hemos señalado en un trabajo anterior (Nazar, 2018) es frecuente encontrar tanto en la historiografía, como en la prensa periódica y en el sentido común, la referencia a los archivos o a los documentos de archivo como cualquier rastro, huella o registro que nos haya llegado desde el pasado.

Sin embargo, los Archivos y los documentos de archivo son un tipo de registro particular. Un registro que puede leerse por su contenido y por su contexto de producción, por su contenido y la función que vino a cumplimentar, por su contenido y su historia.

Analizarlos de esta manera nos permite extraer de los documentos mucha más información de la que en el mismo puede leerse en forma literal. Y este punto se vuelve crucial cuando nos estamos refiriendo a documentos producidos por servicios de inteligencia, ya que algunos de los mismos suelen no tener 
"validación diplomática", lo que quiere decir que probablemente no tengan registrada la fecha y/o el lugar de creación, no estén firmados o estén escritos en clave. Eso, a primera vista, suele generar la sensación de que los mismos no tienen una lógica de producción, sino que responden al trabajo arbitrario de funcionarios grises, que se dedicaban a compilar información en función de sus propios criterios y la volcaban en documentos de forma aleatoria, lo que algunos/as investigadores han sugerido asociar a una forma random de recogida de información.

Sin embargo, que en principio no podamos entender las lógicas de producción o los sentidos originarios de los documentos, o que implique mucho trabajo, no quiere decir que no existan. ${ }^{18}$ La temporalidad, no solo de la producción, sino también de las condiciones de los hallazgos, juega un papel importante en las posibilidades de entender los contextos. Los documentos muchas veces se encuentran separados o desmembrados de los otros documentos producidos por la institución de procedencia (valga la redundancia).

Cuando nuestras trayectorias provienen de la investigación social, suele ocurrir que nuestro enfoque está orientado a querer extraer información del contenido de los documentos, y a veces podemos quedar apegados/as al mismo; dejando fuera la pregunta por intentar entender la lógica de producción de los registros. Cuando solo atendemos la información literal que puede leerse de los documentos (el contenido) los vemos como piezas sueltas y la sensación más común ante conjuntos voluminosos es la de perdernos por laberintos infinitos de montañas de papeles, fotografías y claves sin sentido. Como si nos estuviéramos adentrando en el laberinto del Minotauro.

En cambio, si adoptamos una perspectiva archivística, intentando observar desde lo general hacia lo particular y organizando la mirada a partir de entender las funciones de la institución productora, el esquema empieza a armarse, se fija el caleidoscopio y Ariadna ofrece su hilo.

Para adoptar una perspectiva archivística es necesario suspender momentáneamente la perspectiva de investigación centrada en el contenido informativo de los documentos, en lo que dicen y nos pueden aportar, y trasladar el foco al conjunto de piezas, pensarlo como un sitio arqueológico al completo, el archivo como fondo documental.

Todas las personas, instituciones y entidades producen documentos a lo largo del desarrollo de sus actividades y tareas para cumplir con sus funciones, el conjunto de esos documentos es lo que denominamos un fondo documental. Desde la archivística, los entendemos como el producto del accionar de cada persona e institución, el sedimento de una actividad continuada.

Por eso decimos que un documento de archivo en tanto testimonio de la actividad desarrollada por una persona física o jurídica, pública o privada, tiene determinadas características particulares. Éstas son: originalidad, organicidad y carácter seriado. Estas características lo distinguen del resto de los documentos, tan válidos como testimonios o soportes de información, aunque de un orden diferente (museológico, bibliotecológico, hemerográfico). Y son estas singularidades las que permiten que determinados documentos de archivo puedan cumplir una de sus principales funciones: ser, además de posibles fuentes para las ciencias sociales, garantes de derecho.

Para que estos documentos puedan ser utilizados como prueba, juzgar responsables, reparar a las víctimas y sus familiares, para que el Estado sostenga sus políticas públicas sobre datos confiables, para que las/los investigadoras/es puedan utilizarlos como fuente para todo tipo de investigaciones, es necesario que estén correctamente identificados, clasificados, descriptos y accesibles.

Entender cómo se produjeron los documentos, para qué, cómo se relacionan entre sí, qué información adicional brindan entendidos en ese contexto de producción; qué les sucedió desde el momento en el que se produjeron hasta llegar a nuestras manos permite que los documentos individuales nos den mucha más información que la que contienen en sí mismos, la que puede leerse directamente. Para ello, es necesario analizar la normativa que reguló a la institución productora a través del tiempo e historizar los diferentes procedimientos administrativos, porque eso permite contextualizar y entender las prácticas habituales de la producción de los mismos y sus recorridos hasta el presente. Nos puede habilitar a identificar posibles 
conflictos de poder que narran subrepticiamente los documentos, así como intentos de ocultamiento, prácticas clandestinas, hechos de corrupción, etc.

Para el Consejo Internacional de Archivos (ICA), el término archivo refiere tanto a la producción documental, a la institución que los preserva, como al lugar específico donde se conservan los documentos. Siendo que entendemos que gran parte de los desplazamientos conceptuales en torno a la palabra archivo se origina en utilizar dicho vocablo para denominar la reunión física de un conjunto de documentos (cualesquiera sean ellos), no la utilizaremos para referirnos al depósito ( $3^{\circ}$ acepción). Para la primera acepción -conjunto de documentos de archivo- también puede utilizarse el concepto de fondo documental, y para referirnos a una institución utilizamos el término en mayúscula (Heredia Herrera, 2006).

Como se mencionó anteriormente una de las particularidades que tienen los archivos, en tanto fondo documental, es que poseen una triple función social, la documentación de archivo se preserva: por ser posible fuente para la escritura de la historia de la sociedad, para la memoria de la institución productora y como garantía en el ejercicio de derechos. Esta triple función, distingue al documento de archivo de otros tipos de documentos; marca su especificidad respecto a la información que contiene y frente a la posibilidad de aportarlo como prueba en un estrado judicial ante un conflicto de derechos.

En la medida en que la documentación de archivo tiene la particularidad de poseer información que se encuentra interrelacionada con otra producida por la misma institución, es que la disciplina archivística reconoce tres principios fundamentales a ser respetados para garantizar que dicha información no se pierda: los principios de procedencia, de orden original y de integridad de los fondos.

El principio de procedencia establece que los fondos documentales sean tratados en forma individual y mantengan su autonomía frente a otros (los documentos de una misma procedencia no deben mezclarse con los documentos de otra), este principio es particularmente necesario de respetar en los Archivos que preservan más de un fondo documental. El principio de orden original, complemento de éste, implica que no se altere el ordenamiento en el que los mismos fueron creados. El principio de integridad, que los documentos de un archivo no deben sufrir fragmentaciones ni eliminaciones no autorizadas ni la adición de elementos extraños de cualquier otra procedencia para mantener su valor de prueba e información. La alteración de cualquiera de estos principios puede volver muy dificultosa la recuperación de la información que contienen los documentos, la posibilidad de indagar acerca de las condiciones de producción y la integridad misma de éstos. La alteración de estos principios destruye la posibilidad de leer los documentos en contexto. De esta manera, el concepto de fondo documental:

no queda determinada por el uso que se pueda hacer del mismo, sino por la estructura interna que presenta y, en último término, reitera la necesidad de conocer exhaustivamente la estructura y el funcionamiento de las instituciones y los órganos productores de los documentos, así como el contexto jurídico-administrativo de la producción documental (Alberch Fugueras, 2003, p. 38).

Por ello, es tan importante diferenciar un fondo documental, de una colección de documentos recolectados en función de uno o varios temas de interés: esto es, reunidos en función de su contenido informativo y cuyo aporte sólo puede ser ése.

Un fondo documental, cuando está tratado archivísticamente, permite analizar la interrelación que los documentos tienen entre sí, y en especial, pueden identificarse las series documentales. Se denomina serie documental a los grupos de documentos que tiene por objetivo cumplir determinada tarea, y para ello repiten (porque se encuentra normada) un determinado procedimiento administrativo.

En ese sentido, se pueden identificar series documentales que han sido elaboradas para su difusión (comunicados de prensa, memorias que serán editadas), otras que probablemente fueran difundidas (actos dispositivos, reglamentos), otras que fueron creadas exclusivamente con la finalidad de circular sólo al interior de la institución y otras que llegan a tener clasificaciones de seguridad estableciendo accesos diferenciados incluso al interior de la misma institución productora. Los archivos de inteligencia están formados en su mayoría por esta clase de documentos, aunque algunas de las series documentales que contenga estén 
formadas por documentos públicos (como los obtenidos por la explotación de prensa, afiches, volantes, etc). En algunas de ellas, en particular si su tipo documental es el expediente, se pueden indagar las diferencias que distintas áreas de una institución tienen respecto a la visión sobre determinado problema, ${ }^{19}$ las disputas internas, las divergencias, las convergencias, en fin, las relaciones de poder que pueden haberse establecido. Incluso la opinión, mirada y/o participación de otros actores que no forman parte de dicha institución (otras instituciones del Estado, de la sociedad civil, individuos o familias, etc.). Si bien en los procedimientos administrativos no quedan registradas las sinceras opiniones de los actores que forman el aparato estatal, sí pueden encontrarse reflejados los deberes ser del momento que cada área plasmó en un escrito respecto a un tema. El tipo de información registrada depende de los requerimientos del procedimiento, por ejemplo: una vez tomada una decisión no queda registro de las mismas en los documentos que se hacen públicos, ya sean los actos dispositivos que resuelven en función de una u otra disputa, o en las memorias anuales. También realizar una mirada diacrónica de las resoluciones que se toman respecto a determinadas series (funciones) nos permite analizar el funcionamiento de las instituciones estatales en forma comparada bajo diferentes regímenes políticos y visualizar las rupturas y continuidades que se dan frente a determinadas prácticas.

Poder identificar la serie documental del documento que estamos utilizando como fuente (tarea que debiera ser realizada y presentada por el servicio de archivo al que estamos acudiendo) nos permite enriquecer el análisis superando la mirada sobre la información literal que contiene el documento permitiendo cruzarla con la información contextual del mismo. En esa línea, las excepciones que pueden encontrarse también brindan una gran cantidad de información.

Lo mencionado, solo es posible si dicho archivo o fondo documental mantuvo su integridad, esto es, si se respetaron los principios de procedencia y de orden original antes mencionados. Si la documentación fue seleccionada (ya sea por su temática, porque menciona a determinadas personas, porque pertenece a determinado período) y extraída de su pertenencia a un fondo sólo podremos utilizarla como fuente en función de la información literal que contiene. Esto es lo que suelen (o deberían) hacer los centros de documentación con las copias de los documentos de archivo, ya que a los mismos les interesa reunir documentos (cualquiera sean ellos) que refieren a una temática. Por eso insistimos en la diferenciación entre Centro de Documentación y Archivo.

Cuando no se brinda un tratamiento integral de los fondos de archivo, sino un tratamiento individual a los documentos se corre el riesgo de caer en un uso instrumental de los mismos, atentando contra sus propias potencialidades. Con uso instrumental de los archivos nos referimos a situaciones donde los documentos son gestionados a partir de la necesidad de cumplimentar una de las funciones sociales de los archivos: ya sea la de brindar fuentes para la Historia, de servir para la memoria institucional o de aportar a la justicia. Al enfocar las tareas en servir a una de dichas funciones, los documentos reciben tratamientos individuales en alguna, varias o todas las tareas archivísticas (preservación, identificación, clasificación, ordenación, evaluación, descripción y acceso) perdiéndose muchas veces la integridad de los fondos y el contexto de producción de los documentos. ${ }^{20}$

Básicamente, la selección deliberada de determinado tipo de documentos o de información para la difusión obtura (por acción u omisión de trabajo) el acceso al resto de la documentación que le da sentido y que complementa su información. Esto que podría ser leído desde otras miradas o con otras técnicas dentro de muchos años, puede colaborar en congelar la memoria; restringir el derecho a saber y atentar contra la posibilidad de que esos documentos puedan brindar información a la Justicia, por más voluntad que exista en contrario. Este tipo de trabajo, sin duda bien intencionado, puede producir un efecto contrario al inicialmente pretendido. Porque si bien, aparentemente, aseguran la conservación a corto plazo de unos documentos determinados (y probablemente descontextualizados) generan dudas sobre la capacidad de las infraestructuras archivísticas permanentes y profesionales, propias de todo Estado.

El tratamiento archivístico de los fondos documentales requiere en primer lugar de la tarea de identificación, que se basa en investigar la entidad productora: reconocer las funciones de la entidad, sus 
cambios normativos, historizar los diferentes procedimientos administrativos, contextualizar e investigar las prácticas habituales de la creación de los documentos.

Asimismo, contar con los contextos de producción implica la necesidad de dar cuenta de la historia archivística de dicho fondo: ¿por qué quedó esto? ¿por qué manos pasó? ¿quién la ordenó? ¿cómo? La historia archivística nos brinda el relato necesario para comprender ese contexto de producción.

Entender la funcionalidad de los archivos de inteligencia nos permite comprender que, si bien las denominaciones de impacto mediático como "archivos de la represión" o "archivos del terror" permiten posicionar en la arena pública su importancia, serán los análisis posteriores los que permitan rastrear ese accionar, aunque en sí mismos no encontremos referencias explícitas de la represión.

Un caso paradigmático en relación con la importancia de integrar los contextos de producción de los documentos para enriquecer la información literal que portan es la declaración de uno de los imputados en la Causa CELS - s/denuncia” (Expte. № 186 - Fo 134 - Año 2006), de la Base Aeronaval Almirante Zar, a partir de la cual se identificaron los documentos de la oficina de inteligencia de dicha base mencionados en el apartado anterior. En la misma, el imputado afirmó: “yo sólo juntaba recortes periodísticos”. En línea con la estrategia de algunos marinos de instalar la duda respecto de los supuestos hechos de espionaje, intentaba negar que se tratara de actividades de inteligencia, y afirmaba que no era sino mera información recopilada, carente de todo interés y profundidad "Es como si usted se pusiera a recortar el diario, eso no es inteligencia” (Muzzopappa, 2018, p. 101). El recorte periodístico aislado, no es más que eso. El registro de recortes periodísticos realizado en base a determinados objetivos institucionales, a partir de una práctica reglada y elaborando un informe desde una división de seguridad, ya es otra cosa.

Como señalamos al iniciar esta presentación, este trabajo es un llamamiento para pensar los archivos desde una perspectiva archivística a modo de sistema de interpretación, en este caso, a partir de la relación que los documentos mantienen entre sí funcionando como un todo. Por ello es que los archivos de los servicios de inteligencia, además de contener información específica sobre el espionaje a determinadas personas u organizaciones, nos brindan mucha información sobre la existencia y el funcionamiento de la comunidad informativa, ${ }^{21}$ leídos en forma interrelacionada nos permiten identificar acciones concretas que no están explicitadas en un documento, y a partir de la identificación de sus series nos permiten conocer sus objetivos de inteligencia, más allá de los declarados.

\section{El Archivo de la DiPBBA en la Comisión Provincial por la Memoria}

Como ya ha sido señalado, el archivo de la DIPPBA es el caso paradigmático de un archivo de inteligencia abierto a la consulta pública tanto en Argentina como en toda Latinoamérica.

Tal como se mencionó al principio del artículo, al disolverse la DIPPBA en abril de 1998, una de las primeras medidas que se tomaron fue autorizar al Equipo Argentino de Antropología Forense a acceder a su archivo para colaborar en la tarea de identificación de víctimas del terrorismo de Estado. En esa primera etapa, y urgidos por los aportes probatorios, se realizó una selección de documentación y un reordenamiento de la selección con criterios temáticos orientados fundamentalmente a los Juicios, lo que produjo la ruptura del orden original de parte de la documentación.

Cuando la Legislatura de la Provincia de Buenos Aires transfirió el Archivo y el edificio completo de la DIPPBA - donde se encontraba el depósito de la documentación- a la Comisión Provincial por la Memoria, en el año 2000, fue para transformarlo en un centro de información con acceso público tanto para las personas directamente afectadas como para aquellas interesadas en desarrollar tareas de investigación y difusión (Ley No12.642). La misma ley desclasificó la documentación, gran parte de la cual tenía originalmente carácter secreto, confidencial o reservado.

Como fue señalado en un trabajo anterior (Caimari y Nazar, 2015) la expectativa social que se generó con el archivo de la DIPPBA fue muy grande, como puede verse en el titular de una nota del diario Página/12: 
"Por primera vez se ven los inmensos archivos de inteligencia bonaerense. Detrás de una puerta gris estaba la verdad" (Vales, 1999).

La apertura de este archivo era presentada como la oportunidad inédita de acceder a información producida por los organismos de seguridad y espionaje durante la última dictadura militar. El entusiasmo, la sorpresa y la urgencia por "sistematizar la información para hacerla pública" se evidenciaban en el artículo.

A partir del momento en que la CPM se hizo cargo del archivo y del edificio, se iniciaron dos acciones relacionadas con la documentación. En primer lugar, se elaboró un inventario topográfico y en segundo lugar se comenzó con las tareas de digitalización, con el fin de garantizar la preservación del material. Un equipo de informáticos realizó las tareas de digitalización y desarrolló un programa de búsqueda llamado Dicum. En 2001, la CPM pidió a las delegaciones de la Policía de la Provincia de Buenos Aires que remitieran la documentación relacionada con el funcionamiento de la ex DIPPBA. El 6 de septiembre del mismo año, las delegaciones de Trenque Lauquen, Mercedes, Quilmes, Bahía Blanca, Mar del Plata y Junín respondieron a dicho pedido. En ese tiempo, además de la digitalización y las necesarias tareas de conservación que la misma requería, se inició un acercamiento general hacia la estructura del fondo que no logró consolidar la tarea de identificación general, sin embargo, produjo algunos informes. Un documento que sería recuperado y utilizado varios años después fue el informe sobre la Mesa Doctrina.

En octubre de 2003 el archivo se abría al público, permitiéndose la consulta de los documentos para personas, familiares e investigadores/ras a partir de la mediación de investigadores/as-referencistas.

En 2005 se inició un proceso de fortalecimiento del área al incorporar a un grupo de veinte becarios/ as para avanzar en las tareas de digitalización, ordenamiento y descripción del archivo en convenio con la Facultad de Humanidades y Ciencias de la Educación de la UNLP. Los/as becarios/as fueron capacitados/ as en los principios fundamentales de la archivística, para lo cual se contrató a una archivista que organizó un curso/taller en la sede de la CPM. Después de ello, se realizaron catálogos selectivos, se visionó y catalogó la documentación en soporte VHS y se inventarió parte del material que no había sido identificado previamente.

Ante la necesidad de capacitar a los/as pasantes en cuestiones vinculadas al trabajo sobre la documentación, la realización del curso/taller mencionado y la asistencia técnica realizada por el Departamento de Archivo Intermedio del Archivo General de la Nación se empezó a evidenciar la necesidad de incorporar una perspectiva integral del tratamiento, una perspectiva archivística. Esto no se había manifestado como demanda anteriormente; ya que había un altísimo grado de satisfacción en torno a la información requerida, por todas/os las/os usuarias/os del Archivo.

En 2007, el programa Memoria del Mundo de UNESCO reconoció al Archivo de la DIPPBA como Patrimonio Documental de la Humanidad. Para ese mismo año, a partir de un cambio en la coordinación del área, se convocó como asesora archivística a la archivista que había sido docente del taller, y se puso en marcha un proyecto de ordenamiento, clasificación y descripción general del fondo documental. La primera tarea encarada fue la realización de un inventario de las unidades de conservación y la numeración de éstas. Esto permitió comprobar, luego de mucho trabajo de deducción, que los documentos no se habían digitalizado siguiendo el orden original de los mismos (que era la utilización de los estantes por "filas"), sino que se había seguido el orden que regularmente se utiliza en archivos y bibliotecas de arriba-abajo por cuerpo de estantería. Los documentos habían sido luego ordenados digitalmente en la base digital en la que se hallaban; pero las unidades de conservación, en el depósito, se encontraban desordenadas y sin relación de continuidad entre unas y otras.

En paralelo, se avanzó en la elaboración del cuadro de clasificación y en la descripción general del fondo, ${ }^{22}$ al tiempo que se inició la elaboración de un tesauro general del fondo DIPPBA a partir de tesauros parciales, ya existentes, de algunas de las secciones. En julio de 2008 se designó personal dedicado exclusivamente a las tareas de descripción archivística, dado que hasta ese momento las realizaba el equipo de trabajo del archivo en simultáneo con otras tareas. 
En el año 2010 la descripción general del fondo fue subida a internet y junto a ella, el cuadro de clasificación. La publicación de este cuadro de clasificación, con la descripción de sus secciones y series, es el único caso en el mundo de documentación de inteligencia descripta y disponibilizada en la web; y permitió transformarse en una herramientas para que las personas que quisieran consultar la documentación cuenten con la posibilidad de conocer en el marco de qué funciones y actividades la misma fue generada.

En el año 2013, cuando se cumplían 10 años de la apertura al acceso público, se firmaron convenios con universidades para permitir a los/as investigadores hacer la visualización directa del material en sala; sin requerir de la mediación de referencistas que hicieran la búsqueda.

Asimismo, se siguió avanzando en la normalización de las descripciones y al día de hoy se pueden consultar las mismas vía web, permitiendo que los y las usuarias puedan acceder a la solicitud de documentos a través de referencistas o por sus propios medios.

En el año 2015, el área publicó "La inteligencia policial a través de sus documentos", un desarrollo de la historia institucional de la DIPPBA que presentó las complejas articulaciones del aparato represivo del Estado argentino durante la última mitad del siglo XX. ${ }^{23}$

Ese mismo año, la CPM se presentó como querellante en la causa que investiga las acciones de la Dirección de Inteligencia de la Provincia de Buenos Aires en la planificación y ejecución del terrorismo de Estado. ${ }^{24}$ A partir de la investigación sostenida por el Programa de Justicia por delitos de lesa humanidad de dicho organismo, se elaboró el informe que decidió impulsar la causa para determinar las responsabilidades penales de los integrantes de la DIPPBA. Asimismo, se elaboró un video didáctico para evidenciar por qué la inteligencia es terrorismo de Estado, el cual se basa en explicar los procedimientos de recogida de información y el circuito que cumplían; tarea para la cual se requiere de entender las estructuras de la organización productora de los documentos, sus misiones y funciones, sus relaciones con otras, etc. ${ }^{25}$

A partir de este recorrido, podemos observar que la recuperación y apertura del Archivo no significó, como la apertura de ningún Archivo significa automáticamente, garantía de acceso a la totalidad de la información que podía brindar el fondo documental.

La Comisión Provincial por la Memoria de la Provincia de Buenos Aires, si bien en sus orígenes priorizó el contenido informativo de los documentos abocándose a la digitalización del material con vistas a realizar búsquedas por palabras clave, tiempo después descubrió que otorgarle tratamiento integral (archivístico) al fondo documental DIPPBA mejoraría ampliamente sus potencialidades de información y sus condiciones de acceso, lo que marcó la diferencia fueron las políticas de gestión interna que se dieron en la misma, a partir de las personas que las habitaron.

\section{LOS DOCUMENTOS DE INTELIGENCIA EN EL MARCO DEL FUNCIONAMIENTO DEL ANM}

La creación del Archivo Nacional de la Memoria (ANM) tuvo como objetivo político cumplir con la demanda social de apertura y acceso a los archivos. El artículo $1^{\circ}$ del Decreto 1259/03 establece que las actividades fundamentales del ANM son obtener, analizar, clasificar, duplicar, digitalizar y archivar informaciones, testimonios y documentos sobre el quebrantamiento de los derechos humanos y las libertades fundamentales en que esté comprometida la responsabilidad del Estado Argentino y sobre la respuesta social e institucional ante esas violaciones. Es decir, entre sus funciones principales, tiene la recopilación de documentos de otras instituciones, sin tener en cuenta el posible impacto que pudiera generar el desmembramiento de los fondos de otras instituciones en base a un criterio temático (memoria-terrorismo de Estado) o temporal (1975-1983).

Su ejemplo se replicó en todo el país, creándose archivos de memoria a nivel provincial. Estos archivos fueron creados en su mayoría, como vimos en el primer apartado, sin estructura, presupuesto, recursos ni documentación a cargo. 
Otro elemento complejo respecto a su surgimiento es que el mismo se creó sin considerar las competencias que el Archivo General de la Nación (AGN) podía tener en la temática. Es decir, se formalizó la existencia de otro Archivo Nacional que no estableció puntos de coordinación con las funciones que el AGN tiene. Esto evidenciaba tanto la falta de articulación de las pocas políticas públicas archivísticas que se sostenían a nivel nacional, como la concepción respecto a cuál era la función social y cuáles podían ser las competencias técnicas para el tratamiento de este tipo de documentos. Fortalecer el rol del AGN como órgano rector en la materia, hubiese permitido implementar desde el mismo la coordinación de buenas prácticas archivísticas, a partir de las asistencias técnicas que realizaba a los organismos del Estado para que sus Archivos estuvieran accesibles y sirvieran como prueba para los juicios. Articuladamente al fortalecimiento de esa tarea, crear un centro de documentación vinculado al accionar del terrorismo de Estado que no implicara el desmembramiento de fondos hubiera significado una acción política de alto impacto y eficientes resultados.

El tratamiento de los documentos centrados en una lógica de recorte temporal, temático o en función de los soportes y/o la materialidad de los documentos (papel, audiovisual, fotografías de distinto tipo) determinó que se crearan agrupamientos documentales que no permitían identificar correctamente a los productores ni se respetaran los principios de la disciplina archivística, con los problemas derivados ya señalados y que especificaremos a continuación.

Como se mencionó anteriormente, el ANM tuvo en custodia entre 2014 y 2019 el fondo del Departamento de Informaciones (D2) de la Policía de la Provincia de San Juan. Durante todo ese periodo de tiempo, no se trabajó desde una perspectiva integral archivística. No se identificó al productor, sus funciones ni su vinculación con los documentos; no se registró el orden original de los mismos, se produjeron una multiplicidad de instrumentos de descripción incompletos, ya que el foco estuvo puesto en digitalizar la documentación sin prever las otras etapas de la tarea más que la captura de imágenes. ${ }^{26}$ Además, se comenzó un trabajo de transcripción de las fichas que no concluyó. A su vez, se realizaron tareas de estabilización preventiva de los documentos, se cambiaron los contenedores de guarda y se digitalizó la totalidad del fondo (excepto las fichas) en formato blanco y negro. La digitalización en este formato no permite obtener copias digitales de alta calidad, pero dicha decisión responde a la optimización de la imagen para el motor de búsqueda y reconocimiento óptico de caracteres (OCR) que se utiliza en el ANM. ${ }^{27}$ Esta política de digitalización, sustentada en la confianza en el OCR como método eficaz de recuperación de la información, no contempló la realización de los procesos de corrección posteriores que garantizan su efectividad. A su vez, este centrarse exclusivamente en la información que contienen los documentos para realizar las búsquedas con un motor por palabras, requiere tener un conocimiento exhaustivo de las herramientas y operadores booleanos $^{28}$ para poder refinar las búsquedas hasta encontrar los documentos. Por lo tanto, al no haberse adoptado una perspectiva archivística en el desarrollo del trabajo sobre los fondos y colecciones, el único método de recuperación de la información que existió durante muchos años en el ANM ni siquiera podía ser utilizado en toda su potencialidad. Otra consecuencia fue la mediatización del acceso a los fondos y colecciones a través de referencistas del área de Investigaciones Históricas del Archivo, que deben realizar las búsquedas y recortes para los/as usuarios/as que consultan.

En el caso del fondo de la D2 de la policía de Mendoza, hubo vínculos institucionales con la Universidad para digitalizar todo el acervo. Como el fondo propio del ANM no se encuentra aún bien organizado, no se puede acceder a recuperar la memoria institucional del organismo que permita dar cuenta de qué trabajo se hizo y cuál no. Hasta ahora, se conoce que fue realizada una migración a los servidores del ANM de 165 DVDs que contienen los prontuarios de personas. Si bien este trabajo, del que se encuentran informes bien detallados, resulta una información valiosa, no se dedicó el mismo tiempo a realizar una descripción general que permita conocer la forma en la que esos DVDs ingresaron fehacientemente al ANM.

Esta dinámica del recorte temporal, temático o por soporte de los fondos documentales reordenándolos en otras agrupaciones continuó por dieciocho años. Recién en el año 2020, se impulsó un proyecto de "normalización" archivística, por lo que se están realizando actualmente procesos de identificación, 
clasificación y descripción de los fondos y colecciones que custodia y definiendo en base a ello una nueva política de acceso que permita eliminar las limitaciones de orden práctico que hoy existen. Durante más de un año, hubo que revisar cada agrupamiento documental para poder determinar si era un fondo o una colección, identificar al productor e intentar reconstruir el contexto de producción y la historia archivística desde el momento de su creación hasta la actualidad. Es decir, se demoró más de un año de trabajo en poder reconstruir la información que se tenía de los fondos y colecciones y poder realizar el primer paso del trabajo técnico archivístico, el de la identificación. ${ }^{29}$

Ejemplos de las consecuencias de identificar erróneamente un fondo o basarse en un criterio temático para pensarlo y trabajarlo, pueden observarse en múltiples casos. Consideramos paradigmático tanto el caso de la documentación del Servicio de Informaciones de Chubut como el agrupamiento documental que se conocía como BANADE, también llamado Censura a la Cultura.

En el caso del SI Chubut, los documentos reprografiados fueron encontrados recientemente dentro del agrupamiento "Causas Judiciales", ya que fueron entregados por el Gobierno Provincial, en julio de 2005, junto con la copia certificada de los 30 cuerpos de la causa 500 que contiene, entre otras, 260 declaraciones de detenidos/as dadas en la Unidad 6 de Rawson durante la última dictadura cívico-militar. La Causa 500 fue iniciada en 1980 a partir de un recurso de amparo presentado por el militante Carlos Kunkel que, con el retorno de la democracia, se fue unificando con otras causas. La copia de la misma fue obtenida a raíz de un pedido realizado a la Justicia Federal por parte del Gobierno Provincial.

Por otro lado, el agrupamiento conocido como BANADE fue denominado de este modo ya que, en marzo de 2000, un empleado del Ministerio del Interior encontró los documentos en una bóveda del edificio del ex Banco Nacional de Desarrollo (BANADE). Este edificio había sido cedido a ese Ministerio durante la presidencia de Carlos Menem. Los documentos fueron identificados como producidos por organismos de inteligencia y al estar la mayor cantidad referidos al periodo de la última dictadura cívico-militar fueron trasladados a la entonces Subsecretaría de Derechos Humanos. En septiembre de ese año, por iniciativa de la Defensora Adjunta en Derechos Humanos, comenzó un relevamiento de la documentación que se formalizó el 20 de Marzo de 2001, con la presentación en el Centro Cultural San Martín de la Ciudad de Buenos Aires del programa de investigación "Represión y Cultura. 1976-1983", que culminó con la publicación de un libro al respecto. Este equipo no trabajó desde una perspectiva archivística el fondo, sino observando los documentos en forma individual, por lo que destacó que la documentación encontrada tenía múltiples procedencias, no pudiendo detectar que eso se debía a tramitaciones propias de las diferentes áreas del Ministerio del Interior que componen el mismo.

Con la creación del Archivo Nacional de la Memoria, el fondo fue transferido a dicha institución. La documentación se encontraba agrupada como "BANADE. Censura a la Cultura", sin haberse realizado ningún tipo de tratamiento archivístico, ni haberse podido ofrecer a la consulta pública los documentos más que en forma individual. En el año 2021, en el marco del proyecto de normalización archivística del ANM se hizo una identificación preliminar que permitió comprender que dicho fondo contenía documentos, producidos entre 1973 a 1992, de la Subsecretaría del Interior del Ministerio del Interior, particularmente de la Dirección General de Publicaciones y la Dirección General de Seguridad Interior. ${ }^{30}$ También que la mayoría de los documentos se vinculan con el seguimiento y tratamiento de los medios de comunicación y publicaciones realizados por ese Ministerio durante la dictadura, pero no exclusivamente. Pueden encontrarse dentro del fondo notas e informes de otras dependencias del Estado nacional y provinciales ya que la Subsecretaría del Interior recibía información proveniente de: a) la Secretaría de Información Pública (SIP) -tales como informes de situación psicosocial y comportamiento de medios-; b) la Secretaría de Inteligencia del Estado (SIDE) -sondeos, encuestas y partes informativos sobre noticias relativas al gobierno-; c) y de los distintos organismos de inteligencia de las Fuerzas Armadas, del Ministerio de Relaciones Exteriores, la Aduana, Correos, Policía Federal, entre otros. 
Durante el trabajo de identificación realizado en el marco del proyecto de normalización archivística se detectaron nuevos agrupamientos documentales producidos por los organismos de inteligencia que formaron parte de la comunidad informativa.

Por su parte, lo que hoy se conoce como Colección Agencia Federal de Inteligencia 02 son documentos producidos entre 1973 y 1985 por el Departamento de Contraespionaje 842 de la Comunidad Central de Contraespionaje de la SIDE. ${ }^{31}$ En dicha colección se encuentran informes y partes de inteligencia, temarios para reuniones, actas de reuniones y distintos tipos de comunicaciones vinculados tanto a la SIDE como a diferentes organismos de inteligencia que integraban la comunidad informativa. Esta colección aún está en proceso de identificación y clasificación, pero se supo que fue creada en el marco de las tareas de búsqueda de documentos ordenada por la Agencia Federal de Inteligencia (AFI), en cumplimiento a lo establecido por la Presidencia de la Nación. Esta tarea de relevamiento fue realizada conjuntamente con personal de la Unidad Fiscal de Investigación del atentado a la AMIA en los distintos archivos de las entonces llamadas Dirección de Terrorismo y Dirección de Contrainteligencia. Como la documentación no guardaba vinculación aparente con el atentado a la sede de la AMIA, pero podía ser utilizada para investigar el accionar de las Fuerzas Armadas entre los años 1976 y 1983, el Subdirector de la AFI remitió las copias de la documentación, con datos personales y/o sensibles disociados, a la Secretaría de Derechos Humanos el 9 de diciembre de 2015. Los documentos, sin embargo, se encuentran amparados por la disciplina del secreto, habiéndole la AFI asignado el código de seguridad 4801, por lo que no se encuentran disponibles para la consulta pública.

A su vez, la colección SIDE ${ }^{32}$ está constituida por un agrupamiento de documentos seleccionados por la Secretaría de Inteligencia del Estado, remitida al ANM por el Juez Federal Ariel O. Lijo, a cargo del Juzgado Nacional en lo Criminal y Correccional Federal N4 Secretaría $N^{\circ} 8$, en el marco de la causa 6859/98, “González Naya, Arturo Félix y otros s/ privación ilegítima de la libertad". La colección consta de 11 sobres que corresponden a cada una de las entregas que fue realizando la SIDE al Juzgado entre noviembre de 2011 a febrero de 2013. Los sobres contienen la información obtenida a partir de consultas realizadas a una base de datos propia del Departamento de Antecedentes de la SIDE referida a la información enviada por el Batallón de Inteligencia 601 del Ejército Argentino y del Servicio de Inteligencia de la Fuerza Aérea (SIFA). Cada entrada contiene ficha de antecedentes de personas con sus datos personales, familiares, antecedentes, partes de información y grado de valoración de la información. Esto demuestra la manera en que funcionaba la comunidad informativa y cómo en la actualidad la información sigue circulando.

Como fue señalado anteriormente, en el ANM la prioridad para la búsqueda de la información estuvo signada por el contenido literal de los documentos. Por ello se estableció como único método efectivo de recuperación de la información el sistema de reconocimiento óptico de caracteres, sin considerar las posibilidades que puede brindar la adecuada identificación, clasificación y descripción archivística (multinivel) de los fondos.

Esta situación tampoco se debió a que no hubiera archivistas en el ANM. Hubo archivistas titulados/as, pero los/as mismos/as no pudieron planificar ni implementar una metodología de trabajo que partiera desde una perspectiva archivística. Se tomaron algunas herramientas propias de la disciplina, como la descripción en formatos estandarizados, sin tener en cuenta el punto de partida principal: la identificación del productor de los documentos, las misiones y funciones en el marco de las cuales los había producido y la historia a partir de la cual dichos documentos habían llegado hasta hoy.

Asimismo, al haberse establecido criterios temáticos para la organización de la documentación, se mezclaron documentos de distinta procedencia, lo cual torna extremadamente difícil poder identificar y clasificar correctamente los fondos documentales, perdiéndose información valiosa de su contexto de producción y la relación entre los diferentes documentos que componen cada fondo.

Como ya se detalló, para intentar recomponer el conocimiento que se tiene de los fondos y colecciones, mejorar las formas de recuperación de la información, así como ampliar las posibilidades de investigación sobre cada agrupamiento documental, el ANM está afrontando el proyecto de normalización archivística 
para el que ya debió invertir más de un año sólo en realizar la primera etapa de identificación, la cual permitió elaborar descripciones generales a nivel de cada fondo y colección, que hoy están a la consulta utilizando el software libre Access to Memory (AtoM).

Otra línea de acción vinculada a una perspectiva archivística en la que se está trabajando es la derogación de la disposición que regula el acceso; la misma otorga al Presidente del ANM la potestad de decidir, en función del/a usuario/a, qué documentos pueden darse al acceso y cuáles no. El hecho de haberse realizado un tratamiento temático sobre los agrupamientos documentales impide, a su vez, establecer condiciones de acceso claras e igualitarias basadas en la identificación de la producción de los mismos. El trabajo de identificación y clasificación actualmente en curso permitirá, también, regular el acceso por serie documental y evitar la mediatización del acceso a través de referencistas.

\section{A MODO DE CIERRE}

Frente al reclamo de apertura de archivos, históricamente las diferentes Fuerzas Armadas y de Seguridad han afirmado que se eliminó toda la documentación de la época referida al accionar represivo. Seguramente por ello, los hallazgos esporádicos de documentación vinculada a inteligencia suelen generar gran impacto mediático; o la posibilidad de que lo generen hace que en algunas ocasiones se le de cobertura de "descubrimiento", a documentos identificados hace tiempo. Incluso, presentando como hallazgos sorpresivos a los sucedidos en los mismos edificios donde funcionaban las dependencias.

Sin lugar a duda han sido las demandas por Memoria, Verdad y Justicia los motores que pusieron en marcha la identificación y puesta al acceso de la mayor parte de la documentación de inteligencia en la Argentina. Sin embargo, la respuesta estatal a estas demandas se ha centrado mayoritariamente en generar políticas de memoria y atender el aporte a la justicia. Por otro lado, en la medida en que los documentos generados durante el accionar represivo clandestino, aquellos que darían cuenta específicamente de las tareas de desaparición de personas y apropiación de niños/as, siguen sin aparecer; ${ }^{33}$ es que destacamos la importancia de analizar otros documentos, vinculados a estas acciones y que no brindan la información en forma directa, sino que necesita ser contextualizada e interrelacionada.

Para ello, proponemos la incorporación de la perspectiva archivística como sistema de interpretación, para poder abordar los documentos de una manera integral, y no individual. Entendemos que el acercamiento tradicional a la documentación presentada fue realizado desde una perspectiva de investigación centrada en el contenido de los mismos, más que en una mirada integral. La misma creación del ANM sin considerar su articulación en relación con el Archivo que tenía competencias rectoras en la materia, el AGN, ni incorporar la perspectiva archivística en los inicios de su gestión; institucionalizó esta perspectiva individual. Esta conceptualización también se asentó en -y retroalimentó- la búsqueda de documentos en función de sus temas, lo que puede observarse en las denominaciones de archivos de la represión, archivos del terror o archivos de la memoria; y en función de recortes temporales, lo que llevó a acotar las búsquedas a determinados períodos (como, por ejemplo, 1975-1983).

Abordar los documentos en forma integral implica comprender la lógica de la producción de los mismos, a partir de reconocer su pertenencia a un fondo documental, identificando en primer lugar a su productor y las misiones, funciones e interrelaciones con otras instituciones en el marco de los cuales se generaron dichos documentos. También reconstruir la historia que atravesaron los mismos hasta llegar a la actualidad, de manera de entender qué parte de esa documentación se puede haber perdido, qué distintos ordenamientos pueden habérseles dado y las razones por las cuales llegaron hasta hoy. En los casos presentados hemos visto cómo han operado estas conceptualizaciones resultando de ello el tipo de tratamiento y finalidad que se le han dado a los documentos; incluyendo casos en que los originales fueron entregados, como un intento de reparación, a las personas investigadas. 
En varias de las presentaciones pudimos observar que los acervos, pasada la etapa de efervescencia mediática por su "descubrimiento" y promesa de creación de instituciones que los albergaran se enfrentaron a las vicisitudes propias de la falta de sanción de normativa, existencia de edificios, condiciones óptimas de preservación, recursos económicos y de personal y/o apoyo político en general. De alguna manera, se vieron abandonados en el mismo proceso de recuperación. En ese contexto, la función del ANM de recopilar la información que estos acervos contenían, se transformó en la única oportunidad de recibir algún tipo de tratamiento documental. Así fue como muchos de estos documentos transitaron por diversos espacios sin que se tuviera en cuenta la importancia de preservar su integridad, procedencia, orden original, condiciones de acceso no discrecional y/o el debido registro de ese transitar.

Eso no quiere decir que los documentos no fueran valorados. La valoración de los mismos se manifestó, entre otras líneas de acción, en la presentación conjunta realizada en el año 2007 de varios de estos acervos al Registro de la Memoria del Mundo, Programa de la UNESCO.

También hemos podido observar las diferencias en las políticas de gestión que se dieron al interior de cada una de estas instituciones a lo largo del tiempo. Surgieron en el marco de políticas generales, pero los desarrollos propios dependieron también de variables vinculadas a la impronta otorgada por quienes coordinaron las tareas, y por las/os trabajadoras/es que las hicieron posible.

En la Comisión Provincial por la Memoria de la Provincia de Buenos Aires, si bien en sus orígenes se priorizó el contenido informativo de los documentos abocándose a la digitalización del material con vistas a realizar búsquedas por palabra, tiempo después se observó que otorgarle tratamiento integral al fondo documental mejoraría ampliamente sus potencialidades de información y sus condiciones de acceso. Así es como hoy puede consultarse la descripción general del fondo, su cuadro de clasificación, la descripción de series y hasta algunos inventarios por internet.

Por otro lado, el Archivo Nacional de la Memoria se inició como un centro de documentación y así continuó hasta el año 2020, estableciendo agrupaciones temáticas de la documentación que ingresaba. Como fue señalado, este tipo de tratamiento derivó tanto en un acceso discrecional a los fondos y colecciones, en la pérdida de información valiosa del contexto de producción e historia archivística de cada agrupamiento documental, en el desmembramiento de fondos y la pérdida de su orden original, así como en la falta de herramientas de descripción integrales que permitieran conocer qué es lo que preserva el ANM. Actualmente, con el proyecto de normalización archivística, se está comenzando a gestionar integralmente el acervo, intentando aplicar la disciplina archivística de forma que permita democratizar el acceso a sus fondos y colecciones, siendo un primer paso fundamental la correcta identificación y, a partir de ello, la puesta a la consulta en línea de las descripciones normalizadas.

A lo largo del desarrollo del presente artículo, hemos visto como la ausencia de una perspectiva archivística en el tratamiento dado a algunos de -o en algunas oportunidades a- estos documentos se ha evidenciado fuertemente en torno a aquellas vinculadas tanto a la identificación del último productor de los documentos, que requiere no confundir al mismo con las instituciones con las que intercambia información, como a la necesaria incorporación de toda la historia archivística por la que han transitado. La aplicación de esta perspectiva requiere de la realización de tareas de investigación vinculadas a analizar los cambios normativos, historizar los diferentes procedimientos administrativos, contextualizar e investigar las prácticas habituales de la creación de los documentos tanto como a reconstruir sus recorridos hasta el presente.

A partir de esto, es que proponemos la posibilidad de adoptar una perspectiva archivística como otra estrategia de análisis de la documentación; pero también, que la afirmamos como una necesidad en el tratamiento de los mismos de manera que se pueda asegurar tanto la preservación de la información que los documentos contienen, como de sus contextos; asegurando condiciones de acceso igualitarias. Esta es la tarea que deberían asegurar los Archivos, ya que su función no es brindar al acceso documentos en forma individual (para eso están los centros de documentación) sino a los documentos en su contexto. 
Esperamos que esta presentación haya evidenciado la radical importancia que tiene esto para que los archivos puedan servir de fuente para la historia, la memoria y el ejercicio de derechos. Y de esa manera colabore en incentivar el reclamo, tanto a las instituciones para la realización de buenas prácticas, como al Estado en la constitución de políticas públicas efectivas que incluyan una perspectiva archivística integral para el tratamiento de archivos. Esta será la única forma de dar cabal respuesta al histórico reclamo: Abran Los Archivos.

\section{REFERENCIAS}

Aguila, G. (2013). Las tramas represivas: continuidades y discontinuidades en un estudio de caso. La Dirección General de Informaciones de la Provincia de Santa Fe, 1966-1991. Sociohistórica, (31). Recuperado de: https://www.so ciohistorica.fahce.unlp.edu.ar/article/view/SHn31a01

Alberch Fugueras, R. (2003). Los archivos, entre la memoria histórica y la sociedad del conocimiento. Madrid: Ed. UOC.

Bohoslavsky, E., y Franco, M. (2020). Represión, violencia estatal e historia en el siglo XX en el Cono Sur. Boletín del Instituto de Historia Argentina y Americana Dr. Emilio Ravignani, (53). https://doi.org/10.34096/bol.rav. n53.8009

Caimari, L. y Nazar, M. (2015). Detrás de una puerta gris. Notas sobre los archivos policiales públicos en Argentina. En C. Aguirre y J. Villa-Flores (Eds.), De las cenizas de la historia. Pérdida y recuperación de archivos y bibliotecas en la América Latina moderna (pp. 117-144). Raleigh: Ed. A Contracorriente.

Galiano, H. (15 de junio de 2009). ¿A que no sabés quién vino a buscar los archivos de la dictadura que se descubrieron hace 20 años? [en el blog Señales]. Recuperado de: https://seniales.blogspot.com/2009/06/que-no-sabes-quien -vino-buscar-los.html

Heredia Herrera, A. (2006). ¿Qué es un archivo?. Madrid: Ediciones TREA.

Muzzopappa, M. E. (2018). Secreto en el Estado : militares, justicia e inteligencia en Trelew. San Carlos de Bariloche: TeseoPress. Recuperado de: https://www.teseopress.com/secretoenelestado

Nazar, M. (2006). Sobre las políticas de la memoria. Boletín de la ANABAD, 56(2), 103-110.

Nazar, M. (2008). Dictadura, archivos y accesibilidad documental. A modo de agenda. En Centro de Estudios Legales y Sociales (CELS), Derechos Humanos en la Argentina. Informe 2007 (pp. 413-442). Buenos Aires: CELS, Siglo XXI Editores.

Nazar, M. (2010). Archivos, memoria y derechos: reflexiones en torno al caso argentino. Comma, International Journal on Archives, 2010(2), 145-158. https://doi.org/10.3828/comma.2010.2.12

Nazar, M. (2018). Secretos, reservados y confidenciales: la producción de información de las fuerzas armadas y de seguridad como fuente para la historiografía. Estudios Sociales del Estado, 4(7), 243-264. https://doi.org/10.35 305/ese.v4i7.151

Nazar, M. (2021). Archives for truth and justice in Argentina. The search for the missing persons. En J. Boel, P. Canavaggio, A. González Quintana (Eds.), Archives and Human Rights (pp. 296-308). Londres: Routlegde. ht tps://doi.org/10.4324/9780429054624

Rosales, N. (7 de mayo de 2021). Una reunión en la AFI para que se abran los Archivos. La Retaguardia. Recuperado de: http://www.laretaguardia.com.ar/2021/05/reunion-AFI-archivos.html?fbclid=IwAR0SV7Ne 1DRPLnkIah-B7p6kKUd4QvVRZrY1HraDnL-yTSoe_UTxAIwIg7Q

Vales, L. (25 de noviembre de 1999). Por primera vez se ven los inmensos archivos de inteligencia bonaerense. Detrás de una puerta gris estaba la verdad. Página/12. Recuperado de: https://www.pagina12.com.ar/1999/99-11/99 $-11-25 /$ pag15.htm

Ortiz, L. (2020). Informantes y auscultaciones. Indagaciones sobre el archivo de inteligencia de la Policía Federal en Córdoba, 1974-1982. Revista Electrónica de Fuentes y Archivos (REFA), 11 (11), 260-277. Recuperado de: http s://refa.org.ar/file.php?tipo=Contenido\&id=261 
Tello, M. (2019). El represor como antropólogo: apuntes para la lectura etnográfica de un manuscrito contrainsurgente. Corpus. Archivos virtuales de la alteridad americana, 9 (2). Recuperado de: https://doi.org/1 $0.4000 /$ corpusarchivos.3092

\section{Notas}

1 Para un análisis historiográfico que referencia la importancia de repensar algunos marcos de lectura sobre la violencia estatal en la Argentina a los fines de articular y pensar en forma integrada la cuestión a lo largo del siglo XX puede verse en Bohoslavsky y Franco (2020).

2 Un ejemplo de ello es el testimonio de Carlos Muñoz "a cada detenido que llegaba a la ESMA se le abría una carpeta con el número de caso; esa carpeta contenía todos los antecedentes, todas las descripciones, todos los antecedentes, lo que el secuestrado había escrito y finalmente había una sentencia. Había una hoja donde se abría el caso, decía dónde había sido secuestrado, a qué organización o a qué grupo político pertenecía, quiénes habían participado en el operativo del secuestro, en qué época, y finalmente la sentencia, la sentencia se sintetizaba en una $\mathrm{T}$ o en una $\mathrm{L}$, la $\mathrm{T}$ representaba el traslado y la L la libertad; yo tuve acceso a esos microfilmes en octubre o noviembre del año 1979, (...) me dijeron que buscara los casos de estas señoras, qué era lo que habían declarado, cuáles eran sus antecedentes, y, bueno, esa noche tuve contacto con los cuatro casetes de microfilmes, pude ver la dimensión de la matanza que había habido dentro de la ESMA, porque había aproximadamente 5.000 casos, y las L, que representaban la libertad, eran realmente muy pocas", Diario del Juicio, publicado originalmente por Editorial Perfil, 23 de julio de 1985, Año 1, N 9, disponible en: https://cdadum.wo rdpress.com/archivo-oral/diario-del-juicio/. Agradecemos a Rocío Tagliabue el habernos facilitado la referencia, que en su momento le fue compartida por Nilda Eloy. Por otro lado, en el año 2009, la Editorial de la Campana publicó un libro titulado "Archivos de la Esma", donde se reproduce un expediente o legajo conteniendo antecedentes, declaraciones e información de operativos de detención de miembros de las FAP. No se menciona cómo se obtuvo.

3 Para más información ver el sitio web del Ministerio de Defensa de la Nación. Archivos Abiertos. Disponible en: http s://www.argentina.gob.ar/defensa/archivos-abiertos

4 A través de la Resolución 409 de noviembre del 2020, la Ministra de Seguridad, Dra. Sabina Frederic creó el "Programa de gestión de bienes culturales, históricos y de valor permanente de la seguridad”, con el fin de gestionar, controlar y dar acceso público al acervo de valor permanente, histórico y cultural de las Fuerzas policiales y de seguridad asignando al titular de la Coordinación de Acceso a la Información Pública la responsabilidad de coordinar el grupo de trabajo encargado de dicho programa. Ver Resolución: http://servicios.infoleg.gob.ar/infolegInternet/anexos/340000-34499 $9 / 344217 /$ norma.htm

5 Una descripción del fondo puede encontrarse en: http://atom.ippdh.mercosur.int/index.php/direccion-de-informaci ones-provincia-de-santa-fe (último acceso: abril de 2021)

6 Disposicion Nº167 del Archivo General de la Provincia de Santa Fe, 23 de noviembre de 1999, disponible en http://w ww.santafe-conicet.gov.ar/sipar/legislacion/disp0167-99.htm

7 Actualmente, dicho APM está trabajando con documentación vinculada al accionar de la policía durante la última dictadura proveniente de un hallazgo en una casa particular https://www.santafe.gob.ar/noticias/noticia/269239/

8 Sobre este archivo puede verse en este mismo dossier el artículo de Sahade, Jaschek y Lanteri “Archivos de inteligencia: imaginarios, saberes, sentidos. La experiencia de la CPM a 20 años de la cesión del archivo de la DIPPBA”.

9 Para más información ver: http://atom.ippdh.mercosur.int/index.php/departamento-de-inteligencia-de-la-provinciade-mendoza-d-3

10 Otra mirada sobre este caso puede verse en el artículo de Muzzopappa y Schnyder del presente dossier.

11 Sobre el caso, puede verse: https://www.fiscales.gob.ar/lesa-humanidad/santiago-del-estero-recuperaron-el-archivo-de 1-d-2-y-trabajan-en-su-preservacion/ y https://www.fiscales.gob.ar/lesa-humanidad/digitalizan-carpetas-con-espionaje -ilegal-realizado-por-la-d2-de-santiago-del-estero/

12 Se desconoce la fecha exacta de la entrega.

13 Para un abordaje de algunos de los documentos de este acervo, puede verse en este mismo dossier el artículo de Gatica y Binder.

14 La reserva de la información clasificada como reservada, confidencial o secreta por razones de defensa o política exterior en ningún caso puede alcanzar a la información necesaria para evaluar la definición de las políticas de seguridad, defensa y de relaciones exteriores de la Nación; ni aquella otra cuya divulgación no represente un riesgo real e identificable de perjuicio significativo para un interés legítimo vinculado a tales políticas.

15 Descripción disponible en: https://www.comisionporlamemoria.org/archivo/fondo-prefectura-zona-norte/

16 Sobre este fondo, puede verse en este mismo dossier el artículo de Muzzopappa y Schnyder.

17 Sobre este caso, puede verse Muzzopappa (2018). 
18 Como ejemplo de la tradición burocrática y las formas de organización de la información, podemos citar la Memoria de la División Investigaciones de la Policía de la Capital del año 1932, cuando al mencionar la creación de la Sección Especial de Investigaciones, en abril de dicho año, explicita que su finalidad primordial consistiría en estudiar el desenvolvimiento del comunismo y poner valla a su propaganda tendenciosa y disolvente. Para ello, en vez de analizar los 68.000 prontuarios de Orden social que no estaban clasificados dividiendo los grupos en sindicalistas, anarquistas y comunistas, se decidió abrir nuevos prontuarios siguiendo la nueva lógica de clasificación. "Hago esta salvedad para poner de relieve que la oficina se ajustó en su iniciación al procedimiento de abrir nuevos prontuarios (...) se dividió el trabajo en dos fases: la administrativa, que comprende todo lo referente al movimiento interno, y la vigilancia general de la calle, que concernía a las personas que actuaban en los locales, a las agrupaciones y demás actividades de sus elementos. (...) En el orden administrativo, se consideró de imprescindible necesidad la existencia de un fichero que sirviese para la obtención de una rápida información y se estableció con dos clases de fichas: una que mantiene vinculación con los prontuarios, para Índice General, la otra única y exclusivamente de información rápida. A esta clase de fichas de información van todos los nombres de las personas cuyas inscripciones aparecen en las libretas de los comunistas y hasta en los papeles de los allanamientos. Se trata de personas que no han sido capturadas ni identificadas aún" (Policía de la Capital, Memoria de la División Investigaciones de la Policía de la Capital del año 1932, Imprenta de Policía, marzo de 1933, pp. 77 y 78 ).

19 Sobre este tema, en particular la forma en que los documentos encarnan y reproducen repertorios culturales políticos de largo aliento, es abordado en este dossier por el trabajo de Muzzopappa y Schnyder.

20 Sobre una presentación de casos puede verse Nazar (2018).

21 Se denomina "comunidad informativa" al agrupamiento e intercambio de información entre diferentes servicios y agencias de Inteligencia, que incluye a las dependientes de las Fuerzas Armadas y Fuerzas de Seguridad, los servicios de información provinciales y la agencia nacional, anteriormente denominada Secretaria de Inteligencia del Estado (SIDE), hoy Agencia Federal de Informaciones (AFI).

22 La descripción general del fondo y el cuadro de clasificación pueden verse aquí https://www.comisionporlamemoria.o $\mathrm{rg} /$ extra/archivo/cuadroclasificacion/

23 Documeto disponible en: https://www.comisionporlamemoria.org/project/historia-institucional-de-la-dippba/

24 Ver nota en: https://www.andaragencia.org/causa-dippba-dossier-la-inteligencia-fue-terrorismo-de-estado/

25 Vídeo disponible en: https://www.youtube.com/watch?v=dCtS2bdgjcY

26 Como ejemplo de buenas prácticas de digitalización de documentos históricos puede verse la Guía General de Digitalización de Documentos, publicada por el Ministerio de Ciencia y Tecnología, disponible en: https://www.arge ntina.gob.ar/ciencia/sistemasnacionales/documentacion-historica/guia-digitalizacion

27 El Sistema Óptico de Caracteres, conocido como OCR por sus siglas en inglés (Optical Character Recognition) es un sistema computarizado de análisis que permite escanear un documento de texto en un fichero automatizado electrónicamente, que se puede editar con un procesador de textos en el ordenador; a la vez que buscar palabras a través de todo el texto.

28 Los operadores booleanos son palabras o símbolos que permiten conectar de forma lógica conceptos o grupos de términos para así ampliar, limitar o definir búsquedas.

29 Hoy puede encontrarse un resultado parcial a través de la plataforma online AtoM: https://catalogo.jus.gob.ar/

30 La descripción se encuentra disponible en: https://catalogo.jus.gob.ar/index.php/fondo-subsecretar-a-del-interior-min isterio-del-interior-de-la-naci-n

31 Para más información ver: https://catalogo.jus.gob.ar/index.php/colecci-n-agencia-federal-de-inteligencia-02

32 Para más información ver: https://catalogo.jus.gob.ar/index.php/coleccion-secretaria-de-inteligencia-del-estado-side

33 Mientras terminábamos de escribir este artículo, integrantes del Encuentro Militante Cachito Fuckman fueron convocados a una reunión por la interventora de la Agencia Federal de Inteligencia, Dra. Graciela Camaño, como respuesta al petitorio con casi 10 mil firmas presentado a la Presidencia de la Nación en diciembre de 2020 solicitando la apertura de la totalidad de los archivos del terrorismo de Estado desde el año 1974 a 1983. Un resumen sobre dicho encuentro y la nueva solicitud de acceso presentada puede verse en Rosales, 2021. 